\title{
LIMITES DIALETAIS
}

\section{Migual Wouk \\ Universidade do Paraná}

Vários lingüistas negaram existissem dialetos. Paul Meyer, secundado por Gaston Paris, defendeu o seguinte princípio: o resultado àa evolução da linguagem aparece apenas sob o aspecto da língua comum de uma regiāo e dos falares em que ela se fraciona. Não existem dialetos naturais, pois é impossível defini-los na totalidade de seus caracteres, a não ser que se faça restrição ao estudo da fala de uma só localidade. Ao contrário, se se levar em conta sòmente um dos caracteres, corre-se o risco de usar processo artificial e com resultados superficiais e não convincentes.

Não existindo dialetos como entidades lingüísticas autônomas e bem caracterizaałas, impossivel será determinar-lhes a área de domínio e os limites geográficos entre êles.

Ả mesma concepçāo chega Johann Schmidt, com a sua "teoria das ondas": os fatos lingüísticos difundem-se à maneira de ondas, em movimento insensivel e ininterrupto, não comportando limites, portanto. Esta afirmação baseia-se na falta de coinciờencia entre as isoglossas, tanto nos dialetos das linguas indo-européias, como nos das línguas românicas.

Antoine Meillet, porém, defendeu os dialetos indo-europeus e provou que era possivel e legítimo demarcar os seus limites, uma vez que se notassem algumas particularidades comuns em determinada área. Mesmo que êsses limites sejam flutuantes, bastará poder definir nessa área certos traços gerais inexistentes em outra área.

Graziadio I. Ascoli, estudando os dialetos ladinos, foi mais longe: admitiu a existencia de limites bem determinados, ainała que com zonas intermediárias, de um dialeto a outro, 
com base em muitos caracteres comuns - modificaçōes nos sons, morfologia e sintaxe de um complexo dialetal, próprias de um certo território.

Paul Meyer considerou impossivel demarcar os limites dialetais, ainda porque os fenômenos fonéticos, morfológicos, sintáticos e léxicos difundem-se isoladamente e interpenetram-se desordenadamente. Por isso, a seu ver, o conceito abstrato de dialeto devia ser substituído pelo conceito concreto: fatos lingüísticos isolados; os limites fonéticos não passam de coincidências de pontos fortuitos.

$\mathrm{Na}$ realidade, se se adotasse êsse ponto de vista, isto é, o puramente lingüístico, não sòmente não existiriam dialetos, como tampouco línguas românicas, mas apenas fatos lingüísticos isolados.

Contudo, as pesquisas dialetológicas, levadas a efeito de oitenta anos para cá, sobretudo após o advento da Geografia Lingüística, demonstraram a indubitável e sempre mais clara a existência tanto dos dialetos como dos limites dialetais.

Êstes não formam linhas precisas, mas feixes de caracteres lingüísticos, uns ao lado dos outros, interpenetrando-se mùtuamente, de modo que não coincidem quase. Forma-se, assim, uma zona lingüística de limite.

E eviởente que dois pontos separados por uma zona lingüistica apresentam um conjunto de caracteres divergentes e notáveis diferenças. No entanto, essas diferenças não estão presentes na consciência dos falantes. Estes não podem sentir com exatidão onde termina o dialeto local e onde começá o outro. Mas, percebem as diferenças dos respectivos tipos dialetais, tomando como base a compreensão mútua. Se esta existir, tratar-se-á do mesmo dialeto; se não, o limite dialetal foi transposto. Para julgarem as divergências dos tipos dialetais, os falantes apegam-se mais à diversidade do acento, da entonação musical, da pronúncia e do vocabulário.

Não há dúvida, se é difícil delinear o limite, por exemplo, entre o francês e o provençal, pois, sendo línguas de mesma origem e a passagem de uma a outra é insensível, 
não existe oposiçāo contrastante entre elas, mais difícil será estabelecer as linhas de demarcação dentro do mesmo domínio lingüístico. As isoglossas não coincidem, sāo independentes umas das outras, e as particularidades lingüisticas nunca se apresentam em áreas de mesma extensão.

Por que não é possivel determinar os limites exatos entre os dialetos? Porque as primitivas divisões territoriais, políticas, administrativas ou eclesiásticas (dioceses, feudos, províncias, etc.), apresentando, a princípio, caracteres mais ou menos uniformes na linguagem, com o tempo, devido às vicissituađes politicas ou sociais, tiveram alterada a sua posição e extensão, entraram em variadas combinações e, em geral, estabeleceram relações entre si e com outras regiões mais distantes.

Divisōes políticas e administrativas, acidentes geográficos naturais (montanhas, desertos, rios, etc.) não constituíram sempre obstáculos intransponíveis às comunicaçōes e aos movimentos sociais das migraçōes. Por isso, os entrelaçamentos dos traços lingüísticos, por vêzes, tornaram-se extremamente complexos e dificeis de deslindar.

Os Alpes Ocidentais, entre a França e a Itália, por exemplo, não impediram o intercâmbio lingüístico. E ởigna de nota, tanto no litoral, de Nice a Ventimiglia, como terra a dentro, entre a área do franco-provençal e o Piemonte, correspondência das características lingüisticas. Qual a razão de tão surpreendente limite dialetal? A história dessa zona de transição explicará o fato:

$\left.1 .^{\circ}\right)$ Augusto reuniu os povos romanizaơos das duas vertentes em uma só província ađministrativa, para melhor controlar os passos alpinos;

2. ${ }^{\circ}$ ) mais tarde, os lombardos cederam Susa e Aosta à França;

$\left.3 .^{\circ}\right)$ mesmo na organização eclesiástica, ambos os lados pertenceram à então diocese de Vienne, à Provincia Viennensis; 
$\left.4 .^{\circ}\right)$ os dois flancos dos Alpes Ocidentais pertenceram durante séculos à Casa de Sabóia, originária de Chambéry. A língua oficial era o francês, mesmo no Piemonte, onde só no século XIX o italiano ganhou terreno e se impôs como língua oficial.

Por isso, a vertente italiana, tendo gravitadio para o ocidente, desde muito tempo, lingüisticamente pertence ao território provençal e franco-provençal, e os Alpes não formaram limite dialetal.

Outro exemplo típico, de mesma significação, encontramos na Romênia. Os Cárpatos também não formaram limite dialetal. Até o fim d’a $1 .^{\text {a }}$ guerra mundial, os romenos da Transilvânia pertenceram à Hungria, e os Cárpatos eram a fronteira política com a Romênia. Contud'o, não se formou dialeto romeno independente na Transilvânia, porque essa montanha não impediu o contato contínuo de uma região com outra. Além disso, do lado húngaro as cidades não eram centros políticos, culturais e religiosos, que pudessem reagrupar os romenos, e tão sòmente mercados para o comércio.

O mesmo se dá na região dos Pirineus, onde o gascão se encontra estreitamente ligado aos idiomas da Espanha setentrional (aragonês e catalão) e o catalão ao provençal. O gascão forma um elo entre o francês e o espanhol, e o catalão, entre o provençal e o espanhol.

Nos Apeniros, porém, corre uma linha (Spezzia-Rimini) que separa os dialetos setentrionais dos outros da península. Em nenhuma outra região da Itália é tão notável o limite dialetal, porque o obstáculo natural foi reforçado por outros fatôres: étnicos, históricos e culturais, distintos em um lado e outro.

Assim, vemos que uma cadeia de montanhas ou outra barreira qualquer somente formam limite dialetall quando impedem as comunicações e o intercâmbio étnico, histórico, cultural. 
$\mathrm{Na}$ realidade, portanto, são os fatôres históricos e culturais que criam e determinam êsses limites, haja ou não obstáculos geográficos.

Notamos, por essa razão, entre os grandes grupos lingüísticos em que, mais por interêsses didáticos que pròpriamente cientificos, costuma-se dividir a România atual - galo-romance, ibero-romance, italo-romance, reto-romance e balcano-romance - amplas áreas de transição.

Além do exemplo referido linhas acima, com respeito aos falares pirenaicos, poderiamos apontar mais alguns.

O dalmático-velhoto, falado na península da Istria, recoberto por estrato reto-romance (o friulano), depois, por um estrato veneziano, e finalmente por outro, eslavo, forma um elo entre o romance oriental e o ocidental. Primitivamente apresentava caracteristicas do romance oriental; atualmente pende mais para o ocidental.

O complexo dialetal do norte da Itália, e de moào particular os dialetos galo-itálicos (entre os quais o lombardo) constituem também área de transição entre o tipo italiano (toscano) e o galo-romance. Por outro lado, nota-se transição para a área do reto-romance, a ponto de se haver ăuvidado por longo tempo da individualidade lingüística dêste último, isto é, atí as provas em contrário apresentaăas por Ascoli em "Saggi Ladini".

O grupo franco-provençal, por sua vez, estabelece um liame entre o reto-romance e o tipo do francês do norte e entre êste e o provençal. Do provençal, insensivelmente, através do catalão, faz-se a transição para o espanhol e as outras línguas ibero-romances.

De modo que, apesar da posição peculiar do francês no conjunto das linguas românicas, podemos ressaltar a continuidaơe do território lingüistico da România Ocidental e a passagem gradual de um grupo a outro, o que tem causado dificuldacoes aos lingüistas na configuração exata dos vários grupos, como, de modo especial, ocorreu com o catalão. Enquanto Menéndez Piđal e Amado Alonso nāo provaram a 
sua originária ligação com o grupo ibero-romance, o catalão foi considerado um simples dialeto do provençal, transplantado para a Catalunha no século VIII. ${ }^{\circ}$, por ocasião da retirada dos árabes.

Concluindo: Se os limites lingüísticos não se acham cingidos às fronteiras políticas e às naturais đivisões geográficas, é porque êles foram determinados histórica e culturalmente, no mais amplo sentido. Entre os fatos lingüísticos isolados, a que alude Paul Meyer, há um liame causal de caráter histórico, o qual determina as relações entre os falantes, ora favorável, ora desfavoràvelmente. Por isso, os limites dialetais são vivos e mutáveis: resultado đe fatôres sociológicos, cuja ação não cessa nunca. "Ce qui décide des concordances linguistiques ce sont des faits de civilisation", adverte Antoine Meillet.

Não exclusivamente as divisões eclesiásticas antigas, como querem Morf e Merlo; nem só as invasões germânicas, na opinião de $\mathrm{W}$. von Wartburg, ou outros movimentos d'emográficos isolados através dos séculos, mas todos sucessivamente ou ao mesmo tempo contribuíram a criar a moderna polícromia dialetal românica. Terminemos com as palavias de Bruneau, citado por Serafim da Silva Neto:

"Les patois actuels sont l'aboutissment de quinze siècles d'histoire. . Irrégulières et confuses dès l'origine, ces frontières sont devenues plus irrégulières et plus confuses encore au cours de quinze siècles de vie commune et d'influences réciproques". 